\title{
Peranan Orangtua Dalam Mengantisipasi Perilaku Lgbt Di Kalangan Remaja Kristen di Kota Batam
}

\author{
Fredy Simanjuntak ${ }^{1} *$ Putri Marryam Samaeri Duha, ${ }^{2}$ Yudhy Sanjaya $^{3}$ \\ Prodi Teologi, STT Real Batam \\ Prodi Teologi, STT Real Batam \\ Prodi Teologi, STT Real Batam \\ fredygrace@gmail.com
}

\begin{abstract}
Issues regarding lesbians, gays, bisexuals and transgender people have become phenomena that have occurred over the last ten years, although it turns out that this issue is no longer a product of modernity. Given that the vulnerable age groups affected by this phenomenon are teenagers so it is important to be addressed by Christian parents. Furthermore, the development of technology and the current of the digital era is inevitable whether it is realized or not as well as the media which has the potential to transmit western cultures related to LGBT issues. This research design is a descriptive study with a critical analysis approach. The purpose of this study is to assist parents in anticipating the deviation of Lesbian, Gay, Bisexual and Transgender (LGBT) behavior in adolescents as early as possible. It is hoped that through this research, parents can optimize their education and function in adolescent education in the family.

Keywords: Role, Parents, Anticipating, Behavior, LGBT
\end{abstract}

\begin{abstract}
Abstrak
Isu mengenai lesbian, gay, biseksual dan transgender menjadi fenomena yang terjadi selama lebih dari sepuluh tahun terakhir, walaupun ternyata bahwa isu ini sudah bukan merupakan produk dari modernitas. Mengingat bahwa Kelompok usia yang rentan dijangkiti oleh fenomena ini adalah para remaja sehingga penting untuk disikapi oleh orangtua Kristen. Selanjutnya perkembangan teknologi dan arus dari era digital tidak dapat terhindarkan yang disadari atau tidak juga sebagai media yang berpotensi menularkan budaya-budaya barat yang berkaitan dengan isu LGBT. Design penelitian ini adalah penelitian deskriptif dengan pendekatan analisis kritis. Tujuan penelitian ini adalah untuk membantu orangtua dalam mengantisipasi penyimpangan perilaku Lesbian, Gay, Biseksual dan Transgender (LGBT) pada remaja sedini mungkin. Diharapkan melalui penelitian ini Orangtua dapat mengoptimalkan didikan dan fungsinya dalam pendidikan remaja di keluarga.

Kata kunci: Peranan, Orangtua, Mengantisipasi, Perilaku, LGBT
\end{abstract}

\section{PENDAHULUAN}

Dalam Sebuah hasil riset yang dipaparkan oleh Sell, Wells \& Wypij, mengenai perilaku homoseksual dan ketertarikan dengan sesama jenis seperti Gay, Lesbian dan transgender. Anggapan terhadap perilaku ini dalam artian menganggap dirinya memiliki kecenderungan berbeda dimulai saat berusia muda. Perilaku ini umumnya dijumpai sejak usia 15, prevalensinya pada pria, di Amerika 20.8\%, UK 16.3\%, dan Amerika 18.5\%. Sedangkan pada kelompok wanita masing-masing $17.8 \%, 18.6 \%$, and $18.5 \%$. Keadaan ini 
memperlihatkan kelompok usia sekolah adalah usia yang rentan untuk mulai terlibat dalam hubungan sesama jenis. ${ }^{1}$ Sementara keputusan untuk menjadi homoseksual kebanyakan terjadi pada usia dewasa muda ${ }^{2}$ atau pada usia ketika mereka kebanyakan menjadi mahasiswa.

LGBTQ (lesbian, gay, biseksual, transgender) merupakan salah satu budaya negara barat yang saat ini di beberapa negara mendapat hak penyetaraan dan dilegalkan secara konstitusi. Bentuk dari penyimpangan orientasi seksual LGBTQ adalah menyukai sesama jenis, menyukai dua jenis sekaligus, mengganti jenis asli dengan lawan jenisnya, dan mengeksplorasi identitas jenis dan orientasi seksualnya. Fenomena ini tentu sangat bertentangan dengan kultur ketimuran Indonesia yang menjunjung tinggi norma dan adat kesusilaan terlebih dalam hal sensitif seperti perilaku seksual menyimpang.

Lebih jauh lagi media online Kabar24.com meliput fakta mengenai perilaku menyimpang salah satunya adalah berdasarkan data dari Badan Pemberdayaan Perempuan dan Perlindungan Anak Provinsi Kepulauan Riau (Kepri) ada sekitar 3.000 pelajar di Kota Batam Kepulauan Riau diduga sebagai lelaki penyuka lelaki (LSL). Bahkan menurut salah satu anggota DPRD Kepri, Suryani di Batam Anak-anak berusia di bawah 18 tahun itu terkumpul dalam beberapa komunitas LSL. Suryani menduga, selain pelajar, perilaku LSL, Lesbian, Gay, Biseksual dan Transeksual di Batam juga banyak di kalangan pekerja industri, terutama yang tinggal di asrama-asrama pekerja. ${ }^{3}$

Oleh karena itu orangtua Kristen perlu memberi perhatian lebih kepada anak-anak, agar terhindar dari perilaku LSL dan LGBT. Terlebih di zaman informasi, zaman digital atau zaman media baru adalah sebuah periode sejarah pada permulaan abad ke-20 dan dikarakterisasikan oleh perlalihan cepat teknologi informasi.

Indonesia sudah menapaki era dimana semua serba digitalisasi dan otomatis. Hampir semua sektor mengalami banyak perubahan yang tak bisa dibendung. Dengan kemunculan era digital mampu membawa arus besar masuk ke dalam gaya hidup masyarakat termasuk remaja-remaja yang baru menapaki masa-masa baru dalam lingkungan hidupnya. Dalam hal ini, budaya-budaya luar yang menurut mereka merupakan trend akan sangat mundah menarik perhatian untuk diikuti. Ketidak sadaran masyarakat akan hal ini, menjadi permasalahan di dalam pergaulan para penerus bangsa dikemudian hari. ${ }^{4}$

\footnotetext{
${ }^{1}$ Randall L. Sell, James A. Wells, and David Wypij, "The Prevalence of Homosexual Behavior and Attraction in the United States, the United Kingdom and France: Results of National Population-Based Samples," Archives of Sexual Behavior 24, no. 3 (June 1995): 235-248, http://link.springer.com/10.1007/BF01541598.

2 Sigit Cahyo Nugroho, Siswati, and Hastaning Sakti, "Pengambilan Keputusan Menjadi Homoseksual Pada Laki-Laki Usia Dewasa Awal” (2010): 1-20, http://eprints.undip.ac.id/11145/1/Jurnal_-_Sigit_Cahyo_N__M2A005074.pdf.

${ }^{3}$ Nancy Junita, "FENOMENA LGBT: Sekitar 3 Ribu Pelajar Di Batam Diduga Gay," Kabar24.Bisnis. Com, 2016, https://kabar24.bisnis.com/read/20160212/78/518490/fenomena-lgbt-sekitar-3-ribupelajar-di-batam-diduga-gay.

${ }^{4}$ Gunarsa Singgih D and Yulia Singgih D, Psikologi Remaja (Jakarta: BPK Gunung Mulia, 2003).
} 


\section{METODE}

Penelitian ini berbasis studi literature yang dilakukan dengan mengkaji serta menggali berbagai teori melalui buku, jurnal, media dan fakta yang ada pada masyarakat.

\section{HASIL DAN PEMBAHASAN \\ Isu LGBT}

Setelah Adam dan Hawa jatuh ke dalam dosa maka mereka diusir dari Taman Eden (Kejadian 3:23-24). Maka sejak saat itu dosa mulai bermutasi ke dalam berbagai bentuk dan perbuatan termsuk pembunuhan Habel oleh Kain. Alkitab menarasikan bagaimana manusia telah berbuat jahat dan kecenderungan hatinya semata-mata kepada yang jahat (Kejadian 6) kejahatan lain yang terus meningkat termasuk dosa seksual, yaitu homoseksual terjadi di Sodom dan Gomora. Sementara Tuhan memberikan ketetapan yang jelas secara lisan di zaman sebelum era Taurat. Sebagai contoh peringatan bagaimana Tuhan membumi hanguskan kota Sodom dan Gomora (Kejadian 19:28-29). Murka Allah yang tercatat dalam sejarah Alkitab menunjukkan secara terus terang akan kejahatan penduduk Sodom dan Gormora yang berkaitan dengan penyimpangan seksual yang dilakukan di zaman itu. Alkitab menyebutkan narasi yang jelas bagaimana seluruh kota itu dipenuhi dengan perilaku Sodom dari yang termuda sampai yang tertua.

Dengan Jelas kemudian Tuhan menurunkan Taurat melalui Musa dimana Hukum mulai dibuat secara tertulis. Imamat 18:22,29 mencatat, "bahwa seorang pria dilarang secara keras bersetubuh dengan sesame pria sama seperti bersetubuh dengan seorang perempuan. Bahkan konsekuensi yang jelas tertulis bahwa persetubuhan yang demikian disebut sebagai kekejian dan harus dilenyapkan (Imamat 18:22, 29). Perintah ini begitu mudah untuk dipahami Sangat jelas. Dalam Era Perajanjian Lama homoseksual merupakan suatu penyelewengan secara sesksual yang dibenci oleh Tuhan.

Dalam masyarakat Indonesia Perilaku LGBT masih dikategorikan sebagai penyimpangan seksual. Adat-istiadat yang kuat masih belum dapat menerima perilaku demikian. Meskipun LGBT merupakan fenomena yang terjadi di dalam budaya masyarakat di berbagai belahan dunia namun di Indonesia sendiri belum ada perlakuan khusus secara legal oleh negara untuk mengakui dan mendukung pelaku maupun activist yang berkaitan dengan LGBT. Hal itu tidak mengherankan karena hampir secara menyeluruh kebudayaan Indonesia masih kental dengan ajaran moral, etika dan agama.

Khilman Rofi Azmi membenarkan realita di atas hampir setiap agama melarang perbuatan yang mengacu pada lesbian, gay bisexsual dan transgender. Kecuali pada transgender yang mungkin dikarenakan adanya perubahan kelamin secara tidak sengaja dan bersifat alamiah yang memungkinkan konseli untuk berubah atau berganti kelamin. Larangan agama menjadi aspek yang harus dipegang oleh setiap konselor serta profesi helper lainnya seperti psikolog dan psikiater untuk memberikan perlakuan dan pengetahuan 
tentang bahaya lesbian, gay bisexsual dan transgender serta resiko dan konsekuensi dari lingkungan, agama dan nilai-nilai moral yang menyertainya. ${ }^{5}$

Sitilah LGBT ini merupakan istilah yang digunakan sejak tahun 1990- ${ }^{6}$, menggantikan frasa"komunitas gay" karena istilah ini dinilai lebih mewakili kelompokkelompok yang "mengisi"istilah tersebut secara lebih rinci. LGBT diartikan dalam kategoru LGBT: 1) Lesbi: ini merupakan kelom perempuan yang memiliki ketertarikan secara fisik, emosional dan spiritual dengan perempuan lain; 2) Gay: INi merupakan kelompok laki-laki yang saling tertarik secara fisik, emosional dan spiritual; 3) Biseksual: sementara kelompok ini adalah merupakan kelompok yang memiliki ketertarikan ganda baik dengan lawan jenis maupun dengan sesame jenis baik secara fisik, emosional dan spiritual; 4) Transgender: ini merupakan kelompok orang yang memiliki asumsi dan identitasnya bukanlah sesuai dengan anatomi kelamin bawaan mereka, sehingga sering memilih untuk melakukan operasi ganti kelamin sesuai dengan asumsi jenis kelamin yang mereka terima. ${ }^{7}$

Menurut Roby Yansyah dan Rahayu isu mengenai LGBT saat ini sudah berada pada tatanan global, keberhasilan penyebarannya dicapai melalui serangkaian gerakan proLGBT yang telah ada sejak lama. Fenomena ini didukung dengan adanya deklarasi HAM universal (Universal Declaration of Human Rights) pada tahun 1948, serta reformasi politik dan demokratisasi yang sering “disalah pahami”sebagai proses liberalisasi dan kebebasan mengekspresikan diri. ${ }^{8}$

\section{Peranan Orangtua}

Menurut Bakhoh Jatmiko, rumah tangga Kristen seharusnya menjadi lingkungan untuk mengajar anak-anak tentang hakekat seksualitas manusia yang bersifat suci dan menunjukkan bagaimana artinya dipenuhi dalam konteks kasih, kesetiaan dan kesabaran.

Para pendeta dan pendidik Kristen kita seharusnya menyatakan dengan jelas pengertian Kristen tentang hakekat seksual manusia, dan mendorong orang Kristen untuk menikmati keindahannya yang benar serta dengan semangat menentang pengkhianatan atau penyimpangannya. ${ }^{9}$

\footnotetext{
${ }^{5}$ Khilman Rofi Azmi, "Enam Kontinum Dalam Konseling Transgender Sebagai Alternatif Solusi Untuk Konseli LBGT.," Jurnal Psikologi Pendidikan dan Koseling 1, no. 1 (2015): 50-57.

${ }^{6}$ Sinyo, Anakku Bertanya Tentang LGBT: Panduan Lengkap Orangtua Muslim Tentang Dunia LGBT (Jakarta: Elex Media Komputindo, 2014).64

7 “APA (American PsychologicalAssociation).," 2015, n.d., www.apa.org/pi/lgbt/resources/sexualitydefinitions.

${ }^{8}$ Roby Yansyah and Rahayu Rahayu, "GLOBALISASI LESBIAN, GAY, BISEKSUAL, DAN TRANSGENDER (LGBT): PERSPEKTIF HAM DAN AGAMA DALAM LINGKUP HUKUM DI INDONESIA,” LAW REFORM 14, no. 1 (March 26, 2018): 132, https://ejournal.undip.ac.id/index.php/lawreform/article/view/20242.

${ }^{9}$ Bakhoh Jatmiko, "Hakekat Seksualitas Manusia : Perspektif Gereja Kristen Nazarene Di Abad 21 Terhadap Praktek LGBT,’ Sanctum Domine: Jurnal Teologi 4, no. 1 (2019): 29-39.
} 
Setiap anggota keluarga mempunyai peran penting dalam bagian ini. Hal ini selaras dengan apa yang disampaikan oleh Abineno: Di dalam keluarga Kristen, anggotaanggotanya saling mendidik: orang tua mendidik anak-anak; anak-anak "mendidik" orang tua dan anak-anak. mendidik satu dengan yang lain. ${ }^{10}$ Keluarga Kristen harus menjadi "sekolah" pertama bagi anak untuk memahami bahwa seksualitas manusia bersifat suci; bukan sarana pelampiasan nafsu tapi implementasi kasih yang murni dan implementasinya tidak boleh sembarangan tetapi harus menunggu dengan penuh kesabaran hingga sampai kepada pernikahan dan harus disertai kesetiaan.

Menghadapi tantangan pengasuhan dan problematika yang beragam, maka dibutuhkan sinergi pengasuhan orangtua yang solid. Keberfungsian orangtua sebagai sahabat anak, memahami psikologi anak, dan bersikap bijak terhadap anak. Sehingga menjadikan anak memahami bahwa orantuanya adalah tempat terbaik bagi mereka untuk berbagi dan meminta solusi. Juga dengan sinergi, akan memunculkan bonding kuat antara orangtua dengan anak hingga menjadi benteng agar tidak terjerumus pada LGBT.

Orang tua penting memberikan informasi dan edukasi sejak dini dengan bahasa yang sederhana sesuai milestone anak agar anak mampu menjauhi LGBT. Selain daripada masalah social juga perilaku LGBT berpotensi mendistorsi masa depan dan memiliki dampak yang buruk bagi kesehatan secara jasmani. ${ }^{11}$

Bagi masyarakat, khususnya para orangtua dan guru, perlu kiranya untuk lebih peka terhadap dinamika perubahan LBGT. Jangan sampai isu-isu atau gejala LBGT ini luput dari pandangan kita semua. Jika fenomena ini berdampak pada kerusakan nilai moral dan agama, maka hendaknya perlu ditangani secara lebih kompleks dan nyata serta penanganan yang cepat tanggap. ${ }^{12}$

Orangtua menjadi tokoh utama yang memiliki peran sentral dalam pembentukan Kerangka pemikiran atau pandangan dunia tentang pendidikan karakter bagi anak. Perlu pemusatan hubungan antara Orangtua kepada anak yang didasarkan pada perubahan batin dalam diri seseorang. Fredy Simanjuntak menuliskan bahwa pola hubungan merupakan inti dari seluruh pelayanan dan kehadiran Yesus selama melakukan seluruh pekerjaan-Nya di Bumi. Yesus dalam kesehariannya menempatkan diri-Nya di tengah-tengah orang banyak, mulai dari keluarga sampai kepada anak-anak. Apa yang Yesus ajarkan sesuai dengan apa yang Ia lakukan. ${ }^{13}$ Artinya bahwa kekerabatan dan hubungan memainkan peranan yang penting dalam pola asuh orangtua dalam mendidik remaja menghadapi dinamika perubahan social seperti LGBT yang dipaparkan di atas.

\footnotetext{
${ }^{10}$ J. L. Ch. Abineno, Seksualitas Dan Pendidikan Seksuil (Jakarta: BPK Gunung Mulia, 1983).57

${ }^{11}$ Teguh Firmansyah, "Orang Tua Berperan Strategis Cegah LGBT," 2016, https://www.republika.co.id/berita/nasional/umum/16/02/24/o31p3p377-mui-orang-tua-berperan-strategis-cegahlgbt.

${ }^{12}$ Azmi, "Enam Kontinum Dalam Konseling Transgender Sebagai Alternatif Solusi Untuk Konseli LBGT."

${ }^{13}$ Fredy Simanjuntak, "Problematika Disorganisasi Dan Disharmonisasi Keluarga," in Keluarga Yang Misioner, 2018.
} 


\section{Pendidikan Seks Bagi Anak}

Secara umum pendidikan seks (sex education) dapat diartikan sebagai pendidikan tingkah laku yang baik, menjunjung tinggi nilai-nilai kemasyarakatan serta membantu seseorang menghadapi persoalan hidup yang berpusat pada naluri seks yang timbul dalam bentuk tertentu dan merupakan pengalaman manusia yang normal. Dari pengertian tersebut dapat dipahami bahwa pendidikan seks bermaksud menerangkan semua hal yang berhubungan dengan seks dan seksualitas dalam bentuknya yang wajar, tidak terbatas pada anatomi, fisiologi, penyakit kelamin dan perilaku seks yang menyimpang. Tetapi yang terpenting adalah membentuk sikap serta kematangan emosional seseorang terhadap seks. Sedangkan menurut Abdullah Nasih Ulwan, menyatakan bahwa pendidikan seks merupakan sebuah upaya pengajaran, penyadaran dan penerangan tentang masalah-masalah yang berkenaan dengan seks, naluri dan perkawinan. Sehingga jika anak telah tumbuh menjadi seorang pemuda dan dapat memahami urusan-urusan kehidupan, ia telah mengetahui masalahmasalah yang diharamkan dan yang dihalalkan bahkan mampu menerapkan. ${ }^{14}$

Dengan demikian pendidikan seks adalah upaya orangtua dan pendidik lainnya untuk membiasakan perilaku positif yang berkaitan dengan seks, seperti memposisikan peran anak lakilaki dalam pikiran dan perilakunya sebagai anak laki-laki dan memposisi kan peran anak perempuan dalam pikiran dan perilakunya sebagai anak perempuan pula, menjauhkan anak-anak dari bacaan, gambar dan tontonan seks yang belum wajar dikonsumsi oleh anak, menjauhkan anak-anak dari kekerasan seksual, menyampaikan informasi positif tentang seks dan pernikahan yang sesuai dengan usia anak, serta hal-hal negatif yang berkaitan dengan seks sehingga menumbuhkan kesadaran pada anak tentang sex positif dan kapan anak berhak mengenalnya, agar anak-anak menghindari dan menjauhkan dirinya pergaulan bebas, anak-anak dapat menghindari seks negatif yang dilarang oleh norma-norma masyarakat dan agama.

Sedangkan menurut Suryadi, pendidikan seks adalah usaha pemberian informai kepada anak mengenai kondisi fisik baik sebagai permpuan ataupun laki-laki serta konsekuensi psikologis yang berkaitan dengan kondisi anak. Secara umum, pendidikan seks terdiri atas penjelasan tentang organ reproduksi, kehamilan, tingkah laku seksual, alat kontrasepsi, kesuburan dan manepouse serta penyakit kelamin. ${ }^{15}$

\footnotetext{
${ }^{14}$ Safrudin Azis, "Pendidikan Seks Bagi Anak Berkebutuhan Khusus," Jurnal Kependidikan 2, no. 2 (2014): 182-204.

${ }^{15}$ Endang Lestari, "Peran Orang Tua Dalam Memberikan Pendidikan Seks Sedini Mungkin Di TK Mardisiswi Desa Kedondong Kecamatan Kebonsari Kabupaten Madiun. Nugroho," Jurnal Ilmiah Pendidikan 2, no. 2 (2014): 125.
} 
Menurut pendapat Sarwono ${ }^{16}$, dapat dilakukan tindakan untuk mengurangi dan mencegah penyalahgunaan seks, yaitu dengan memberikan pendidikan seks di dalam keluarga, sehinggga akibat-akibat yang tidak diinginkan seperti kehamilan, depresis, maslah psikologis, perasaan bersalah serta penyakit seks menular. Pendidikan seks merupakan hal penting yang harus dibicarakan dan bukanlah sesuatu perihal yang tabu.

Berdasarkan pemaparan di atas, membicarakan seks kepada anak sangat penting. Namun walaupun hal ini penting dalam masyarakat yang budaya masih tertutup sering sekali orangtua tidak terbuka dan sadar untuk membicarakannya. Hal ini tepat seperti yang di tuliskan oleh Maria Tretsakis yan mengatakan bahwa secara keseluruhan justru informasi seks yang diberikan oleh orangtua memiliki pengaruh yang baik untuk melindungi kehidupan masa depan remaja dari komplikasi masalah seks. ${ }^{17}$

Berhubung oleh masa remaja, sebagai masa yang dialami oleh seseorang dengan pengalaman yang signifikan akan perubahan-perubahan dalam diri remaja. Ini merupakan kesempatan yang baik bagi orangtua dalam menjawab dan menjelaskan secara terarah informasi sepeutar seks. Karena remaja pasti diliputi oleh berbagai pertanyaan yang mereka belum ketahui sepenuhnya. Oleh sebab itu perntingnya pendidikan seksual dalam proses kehidupan remaja, dan dapat diberikan menjelang masa remaja supaya mereka memiliki perhatian dan pengetahuan untuk menghindari perilaku seksual yang dapat merugikan maa muda mereka. ${ }^{18}$

Masa remaja adalah masa anak ingin tahu banyak hal tentang perubahan fisik, emosional, dan lainya, sehingga merasa ada yang berbeda terhadap diri mereka, dan pada akhirnya muncullah berbagai-bagai pertanyaan yang sangat mengganggu pemikiran anak reamaja, sehingga membuat mereka menggebu-gebu untuk mencari tahu akan hal yang sedang terjadi pada diri mereka. Masa remaja adalah masa perkembangan transisi antara masa anak dan dewasa yang mencakup perubahan biologis, kognitif dan sosial. Secara biologis remaja mengalami perubahanan fisik seperti perubahan bentuk tubuh, perubahan suara, perubahan hormonal dan lain sebagainya. Perubahan kognitif yang terjadi pada remaja yaitu mampu bernalar secara abstrak dan logis serta pikiran menjadi lebih idealistik. $^{19}$

\section{Penyimpangan Seksualitas Manusia}

Seksualitas meleset dari maksud yang sebenarnya ketika dipandang sebagai suatu tujuan dari diri sendiri atau ketika dibuat murah oleh orang yang memakai seksualitas

\footnotetext{
${ }^{16}$ Dwi Ario Fajar, Susanto Susanto, and Ribut Achwandi, "Strategi Optimalisasi Peran Pendidikan Seks Usia Dini Di PAUD Dalam Menanggulangi Pelecehan Seks Terhadap Anak Di Pekalongan,” Jurnal Litbang Kota Pekalongan 7 (2014): 42-43.

${ }^{17}$ Maria Tretsakis, Seks Dan Anak-Anak (Bandung: Pionir Jaya, 2003). 13

${ }^{18}$ Warih Andan Puspitosari, "Peranan Orang Tua Dalam Pendidikan Seks," Jurnal Mutiara Medika 2, no. 1 (2002): 49-54.

${ }^{19}$ Ellita Novianthy Baganu, "Peran Orang Tua Dalam Memberikan Pendidikan Seks Terhadap Perilaku Seksual Remaja Di GKII Jemaat Tengkapak," 2018.
} 
untuk memuaskan keinginan porno atau hal lain yang tidak senonoh. Kita memandang bahwa semua hubungan seksual yang terjadi di luar ikatan pernikahan heteroseksual (lakilaki dan perempuan) sebagai penyimpangan yang bersifat dosa dari kesucian dan keindahan yang direncanakan Allah. ${ }^{20}$

Firman Tuhan tidak berdiri pada posisi abu-abu atau tidak menyatakan sikap terhadap perilaku homoseksual. Alkitab secara jelas menentang praktek homoseksual dan pernikahan sejenis. Ditegaskan oleh Robert P. Borong dalam bukunya menyatakan, homoseksualitas adalah "penyakit" atau "keadaan abnormal" atau "penyimpangan. ${ }^{21}$

LGBT adalah suatu cara dimana hakekat seksualitas manusia dibengkokkan. Tindakantindakan LGBT sebagai perilaku seksual menyimpang menegaskan posisi Alkitab bahwa tindakan-tindakan seperti itu adalah dosa dan layak menerima murka Allah. Namun sebagai orang percaya kita menerima anugerah Allah yang mampu mengatasi kebiasaan LGBT ini(1 Kor. 6: 9-11).

Dalam Perjanjian Baru, rasul Paulus mengingatkan jemaat Kristen di Roma agar menjauhkan diri dari perilaku penyelewangan seksual dimana laki-laki yang dikuasai nafsu yang menyala-nyala meninggalkan istri mereka dan berbuat mesum dengan laki-laki (Roma 1:27-28). Mereka digambarkan sebagai orang sesat yang tak merasa perlu mengakui Allah. Bagi mereka hidup adalah pemuasan nafsu. Mereka disebut biseksual, yaitu hubungan dengan lawan jenis, tapi juga dengan sejenis. Sementara untuk homoseksual rasul Paulus menyebutnya pemburit (1 Korintus 6:9, 1 Timotius 1:10), sebagai yang bertentangan dengan ajaran sehat dan tidak mendapat bagian dalam kerajaan kekal. Dalam KBBI, kata burit berarti belakang, buntut, dubur, dan memburit atau pemburit menunjuk kepada mereka yang melakukan hubungan sesksual dibagian belakang yaitu homoseksual.

Dengan sangat jelas Alkitab menyatakan sikap atas perilaku seksual menyimpang yaitu homoseksual, biseksual, atau apa yang disebut banci, juga istilah kini trans gender, sebagai hal yang salah, dosa, ajaran yang tidak sehat dan menyesatkan. Entah bagaimana cara berpikir sebagaian teolog liberal yang menyebut homoseksual bukanlah dosa. Apa yang tertulis di Alkitab mereka ingkari, sementara pemikiran liar yang tak berdasar mereka bangun. Menafsir melompat sebebasnya tanpa merasa perlu terikat pada Alkitab yang ditafsirkan.

Berpijak kepada apa yang dikatakan di dalam 1 Korintus 6: 9-11, masyarakat Kristen perlu memahami bahwa perilaku Seksual menyimpang bisa dipulihkan dengan anugerah dan karya Allah. Kuasa Allah diyakini mampu memulihkan dan merestorasi kehidupan seseorang. Lewis B Smedes dalam kaitannya tentang Keselamatan dan Seksualitas menghubungkan antara Injil Yesus Kristus yang adalah kabar baik bagi semua manusia; tidak hanya membawa kepada keselamatan jiwani, tetapi Injil juga akan memulihkan peranan seksual dan mengangkat seksualitas kepada hakekat dan fungsinya. 12 Kabar baik dan anugerah Allah tidak menentang seksualitas, tetapi penyimpangan-

\footnotetext{
${ }^{20}$ Jatmiko, "Hakekat Seksualitas Manusia : Perspektif Gereja Kristen Nazarene Di Abad 21 Terhadap Praktek LGBT."

${ }^{21}$ Robert P. Borrong, Etika Seksual Kontemporer (Bandung: Ink Media, 2006).82
} 
penyimpangan yang ada di dalamnya. kemerdekaan di dalam anugerah Allah adalah kemerdekaan dari, dan kemerdekaan untuk; karunia Allah membebaskan dari penyimpangan-penyimpangan dan tekanan-tekanan; kemudian mendapatkan kebebasan untuk mengasihi dan melayani di dalam kehendak Allah. ${ }^{22}$

\section{KESIMPULAN}

Bagi Orangtua Kristen kiranya penting untuk lebih peka terhadap dinamika perubahan dalam konteks kemasyarakatan. Jangan sampai sebuah fenomena luput dari penglihatan mata sehingga jika fenomena tersebut berdampak pada kerusakan moral dan turunnya nilai agama, maka hendaknya perlu ditangani secara lebih kompleks dan nyata serta penanganan yang cepat tanggap dan tepat. Semakin besar peran orang tua di dalam keluarga dalam memberikan pendidikan seks untuk remaja maka, semakin kecil pula perilaku sekssual menyimpang yang dilakukan oleh para remaja.

\section{KEPUSTAKAAN}

Abineno, J. L. Ch. Seksualitas Dan Pendidikan Seksuil. Jakarta: BPK Gunung Mulia, 1983. Azis, Safrudin. "Pendidikan Seks Bagi Anak Berkebutuhan Khusus." Jurnal Kependidikan 2, no. 2 (2014): 182-204.

Azmi, Khilman Rofi. "Enam Kontinum Dalam Konseling Transgender Sebagai Alternatif Solusi Untuk Konseli LBGT.” Jurnal Psikologi Pendidikan dan Koseling 1, no. 1 (2015): 50-57.

Baganu, Ellita Novianthy. "Peran Orang Tua Dalam Memberikan Pendidikan Seks Terhadap Perilaku Seksual Remaja Di GKII Jemaat Tengkapak,” 2018.

Borrong, Robert P. Etika Seksual Kontemporer. Bandung: Ink Media, 2006.

Fajar, Dwi Ario, Susanto Susanto, and Ribut Achwandi. "Strategi Optimalisasi Peran Pendidikan Seks Usia Dini Di PAUD Dalam Menanggulangi Pelecehan Seks Terhadap Anak Di Pekalongan.” Jurnal Litbang Kota Pekalongan 7 (2014): 42-43.

Firmansyah, Teguh. "Orang Tua Berperan Strategis Cegah LGBT,” 2016. https://www.republika.co.id/berita/nasional/umum/16/02/24/o31p3p377-mui-orangtua-berperan-strategis-cegah-lgbt.

Jatmiko, Bakhoh. "Hakekat Seksualitas Manusia : Perspektif Gereja Kristen Nazarene Di Abad 21 Terhadap Praktek LGBT." Sanctum Domine: Jurnal Teologi 4, no. 1 (2019): 29-39.

Junita, Nancy. "FENOMENA LGBT: Sekitar 3 Ribu Pelajar Di Batam Diduga Gay." Kabar24.Bisnis.Com, 2016.

https://kabar24.bisnis.com/read/20160212/78/518490/fenomena-lgbt-sekitar-3-ribupelajar-di-batam-diduga-gay.

Lestari, Endang. "Peran Orang Tua Dalam Memberikan Pendidikan Seks Sedini Mungkin Di TK Mardisiswi Desa Kedondong Kecamatan Kebonsari Kabupaten Madiun. Nugroho.” Jurnal Ilmiah Pendidikan 2, no. 2 (2014): 125.

Nugroho, Sigit Cahyo, Siswati, and Hastaning Sakti. "Pengambilan Keputusan Menjadi Homoseksual Pada Laki-Laki Usia Dewasa Awal" (2010): 1-20. http://eprints.undip.ac.id/11145/1/Jurnal_-_Sigit_Cahyo_N_-_M2A005074.pdf.

${ }^{22}$ Lewis B. Smedes, Seks Untuk Orang Kristen (Jakarta: Nafiri Gabriel, 2000).88-98 
Puspitosari, Warih Andan. "Peranan Orang Tua Dalam Pendidikan Seks." Jurnal Mutiara Medika 2, no. 1 (2002): 49-54.

Sell, Randall L., James A. Wells, and David Wypij. "The Prevalence of Homosexual Behavior and Attraction in the United States, the United Kingdom and France: Results of National Population-Based Samples." Archives of Sexual Behavior 24, no. 3 (June 1995): 235-248. http://link.springer.com/10.1007/BF01541598.

Simanjuntak, Fredy. "Problematika Disorganisasi Dan Disharmonisasi Keluarga." In Keluarga Yang Misioner, 2018.

Singgih D, Gunarsa, and Yulia Singgih D. Psikologi Remaja. Jakarta: BPK Gunung Mulia, 2003.

Sinyo. Anakku Bertanya Tentang LGBT: Panduan Lengkap Orangtua Muslim Tentang Dunia LGBT. Jakarta: Elex Media Komputindo, 2014.

Smedes, Lewis B. Seks Untuk Orang Kristen. Jakarta: Nafiri Gabriel, 2000.

Tretsakis, Maria. Seks Dan Anak-Anak. Bandung: Pionir Jaya, 2003.

Yansyah, Roby, and Rahayu Rahayu. "GLOBALISASI LESBIAN, GAY, BISEKSUAL, DAN TRANSGENDER (LGBT): PERSPEKTIF HAM DAN AGAMA DALAM LINGKUP HUKUM DI INDONESIA." LAW REFORM 14, no. 1 (March 26, 2018): 132. https://ejournal.undip.ac.id/index.php/lawreform/article/view/20242.

“APA (American PsychologicalAssociation)." 2015, n.d. www.apa.org/pi/lgbt/resources/sexuality-definitions. 